\title{
Effect of Cu Negative Ion Implantation on Physical Properties of $\mathrm{Zn}_{1-x} \mathrm{Mn}_{x}$ Te Films
}

\author{
A.D. Pogrebnjak ${ }^{a, *}$, A.P. Shypylenko ${ }^{a}$, H. Amekura ${ }^{b}$, Y. Takeda ${ }^{b}$, A.S. Opanasyuk ${ }^{a}$, \\ D.I. Kurbatov ${ }^{a}$, I.A. Kolotova ${ }^{a}$, O.V. Klymov ${ }^{a}$ And C. KOzAK ${ }^{c}$ \\ ${ }^{a}$ Sumy State University, 2 Rimsky-Korsakov Str., 40007, Sumy, Ukraine \\ ${ }^{b}$ National Institute for Materials Science, Tsukuba, Ibaraki, Japan \\ ${ }^{c}$ Lublin University of Technology, Nadbystrzycka 38a, 20-618 Lublin, Poland
}

\begin{abstract}
The paper deals with the investigations of structural properties of $\mathrm{Zn}_{1-x} \mathrm{Mn}_{x} \mathrm{Te}$ films, which were fabricated under various deposition conditions using the thermal evaporation method in a closed volume. The surface morphology of the samples was studied, the phase analysis of their structures was performed, the elemental analysis of the films and the crystal lattice constant were investigated. The texture perfection of the films before and after copper ion implantation was evaluated.
\end{abstract}

DOI: 10.12693/APhysPolA.123.939

PACS: 61.05.cp, 61.72.uj

\section{Introduction}

At present, the interest of specialists working in the field of materials science, more specifically in semimagnetic solid solutions $\mathrm{Zn}_{1-x} \mathrm{Mn}_{x}$ Te has developed since their photoluminescence, magnetic and magnetooptical properties were unique allowing fabrication of a number of effective instruments for micro-, opto-electronics, solar power engineering, and spintronics [1,2]. Copper is traditionally employed as a doping impurity activating the photoluminescence, as well as for fabrication of doped ZnTe films of high conductivity [3-5]. The ion implantation is considered to be the most efficient method allowing introduction of this impurity to $\mathrm{A}_{2} \mathrm{~B}_{6}$ compounds [6]. However, the influence of $\mathrm{Cu}$ impurity on the properties of $\mathrm{Zn}_{1-x} \mathrm{Mn}_{x}$ Te solid solutions is poorly studied. The work reports the structural properties and the elemental composition of the $\mathrm{Zn}_{1-x} \mathrm{Mn}_{x}$ Te films deposited using close-spaced vacuum sublimation (CSVS) before and after copper ion implantation.

\section{Methodology of film preparation and investigations}

The thin $\mathrm{Zn}_{1-x} \mathrm{Mn}_{x}$ Te films were deposited on the glass substrates at over $5 \times 10^{-3} \mathrm{~Pa}$ pressure of the residual gases in the chamber. The detailed description of device, which was employed for the film deposition using the CSVS method, was reported in $[7,8]$. The mix material of a semiconducting purity containing $10 \%$ of manganese was evaporated. The temperature of the evaporator was $T_{\mathrm{e}}=800^{\circ} \mathrm{C}$. The substrate temperature varied within the interval $T_{\mathrm{s}}=150-550^{\circ} \mathrm{C}$. The deposition time

\footnotetext{
*corresponding author; e-mail: alexp@i.ua
}

was normally $t=5-15 \mathrm{~min}$, and the layer thickness was 2-8 $\mu \mathrm{m}$. Surface morphology of the films was studied using scanning electron microscopy (REMMA-103-01).

Elemental analysis of films was performed using X-ray characteristic radiation induced by a proton beam [9]. The studies were carried out using the electrostatic accelerator Sokol with the energy of a proton beam up to $2 \mathrm{MeV}$ (Institute of Applied Physics, NAS of Ukraine, Sumy) [10]. Summed-up spectra from several areas of the sample surfaces (particle induced X-ray emission, PIXE) were scanned and point-by-point spectra were studied using the micro-beam ( $\mu$-PIXE). The scanned film area was usually $200 \times 200 \mu \mathrm{m}^{2}$. The transverse size of the probe was $4 \times 4 \mu \mathrm{m}^{2}$, charge $Q=4 \times 10^{-10} \mathrm{C} /$ pixel, raster was $50 \times 50$ pixels, and the scanning step was $4 \mu \mathrm{m}$. The proton energy $E_{\mathrm{p}}$ was $1.5 \mathrm{MeV}$. The obtained PIXE spectra were processed using the GUPIX 3 program. The samples fabricated under optimal conditions $\left(T_{\mathrm{s}}=350^{\circ} \mathrm{C}\right)$ were subsequently doped by implantation of negative $\mathrm{Cu}$ ions of $60 \mathrm{keV}$ energy and the $10^{14} \mathrm{~cm}^{-2}$ fluence using the ion source (NIMS, Tsukuba, Ibaraki, Japan).

Structural studies of the films were performed with the X-ray diffraction device RINT2500MDG in $K_{\alpha^{-}}$ -emission of the chrome anode. Shooting was performed within $2 \theta$ angles from $10^{\circ}$ to $160^{\circ}$ ( $2 \theta$ is the Bragg angle). X-ray radiation was focused according to BraggBrentano. Curves were normalized to the peak (111) intensity of a cubic phase. Phase analysis was carried out by comparing the interplanar spacings and relative intensities of X-ray peaks of the studied samples and the standards of JCPDS [11]. The film textures were measured by the Harris method [12-14]. The $\mathrm{Zn}_{1-x} \mathrm{Mn}_{x} \mathrm{Te}$ powder was used as the standard of a non-textured sample. The lattice constant value of $\mathrm{Zn}_{1-x} \mathrm{Mn}_{x}$ Te films was determined by the position of $K_{\alpha_{1}}$ component of all most intensive lines present in the diffraction patterns. Subsequently, to obtain precise values of constants, we used 
the extrapolation methods of Nelson-Riley and Bradley-Jay $[13,14]$. The separation of the doublet was achieved by the Rechinger method using the package of applied programs DIFWIN.

\section{Investigation results and discussion}

Based on the studies, it was proved that the growth of the $\mathrm{Zn}_{1-x} \mathrm{Mn}_{x}$ Te films was similar to the growth of other chalcogenides $[7,8,15-17]$. The investigated films had the grain size $D=0.50-1.12 \mu \mathrm{m}$ and $l=2-8 \mu \mathrm{m}$ thickness. The grain size increased with the substrate temperature. Electron-microscopic images of the $\mathrm{Zn}_{1-x} \mathrm{Mn}_{x} \mathrm{Te}$ surfaces and their cross-sections obtained at various temperatures of the substrates are shown in Fig. 1. The analysis demonstrated that the calculated values of $D$ were somewhat lower than those of the ZnTe films deposited under similar conditions $[16,17]$.

The PIXE method, which was employed to study the $\mathrm{Zn}_{1-x} \mathrm{Mn}_{x}$ Te films, showed the presence of manganese in several surface areas. The analysis of the element compositions of the initial films is summarized in Table I. It was shown that the average concentration of manganese in the samples was $1.62-3.04$ at.\%. When the substrate temperature increased from $T_{\mathrm{s}}=350{ }^{\circ} \mathrm{C}$ to $550{ }^{\circ} \mathrm{C}$, it decreased. In addition, the investigated films were characterized by the dominating content of tellurium compared with zinc $\left(C_{\mathrm{Zn}} / C_{\mathrm{Te}}=0.70-0.87\right)$. The uncontrolled and residual impurities were not identified in the studied samples. Scanning the sample surfaces by the proton beam ( $\mu$-PIXE) we found that manganese was uniformly distributed over their areas.

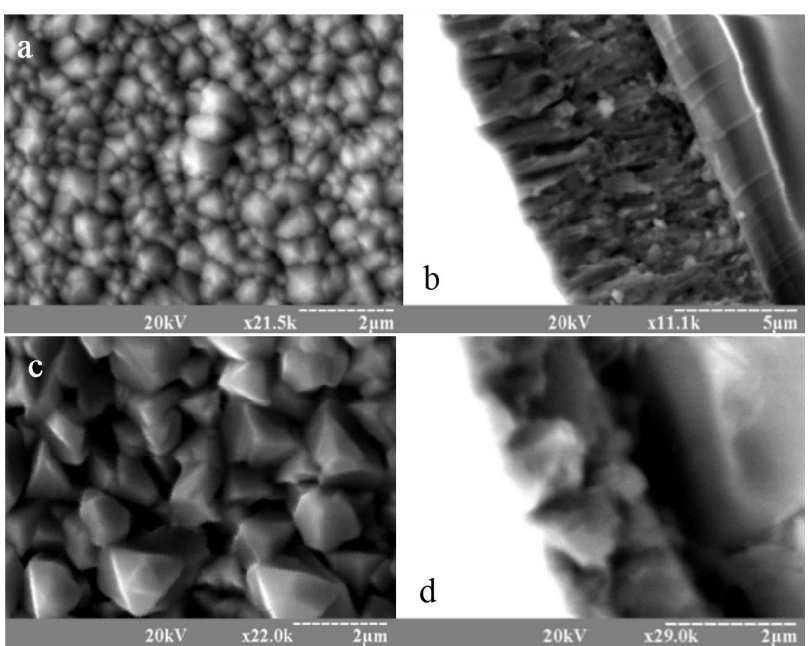

Fig. 1. SEM images of surface (a, c) and cross-section of the $\mathrm{Zn}_{1-x} \mathrm{Mn}_{x}$ Te films (b, d) obtained at $T_{\mathrm{e}}=800^{\circ} \mathrm{C}$ and deposited at the substrate temperature $T_{\mathrm{s}}\left[{ }^{\circ} \mathrm{C}\right]: 150$ $(\mathrm{a}, \mathrm{b}), 550(\mathrm{c}, \mathrm{d})$.

Element composition of the $\mathrm{Zn}_{1-x} \mathrm{Mn}_{x}$ Te films.

TABLE I

\begin{tabular}{c|c|c|c|c|c|c|c|c|c}
\hline \hline$T_{\mathrm{s}}\left[{ }^{\circ} \mathrm{C}\right]$ & $T_{\mathrm{e}}\left[{ }^{\circ} \mathrm{C}\right]$ & $\mathrm{Zn}[\mathrm{wt} \%]$ & $\mathrm{Mn}[\mathrm{wt} \%]$ & $\mathrm{Te}$ [wt\%] & $\mathrm{Zn}$ [at.\%] & $\mathrm{Mn}$ [at.\%] & $\mathrm{Te}$ [at.\%] & $C_{\mathrm{Zn} / C_{\mathrm{Te}}} C_{\mathrm{Zn}+\mathrm{Mn} / C_{\mathrm{Te}}}$ \\
\hline 350 & 800 & 28.90 & 1.70 & 69.40 & 43.47 & 3.04 & 53.49 & 0.81 & 0.87 \\
450 & 800 & 30.55 & 1.09 & 68.36 & 45.68 & 1.94 & 52.38 & 0.87 & 0.91 \\
550 (region 1) & 800 & 26.22 & 1.02 & 72.76 & 40.51 & 1.88 & 57.61 & 0.70 & 0.74 \\
550 (region 2) & 800 & 26.34 & 0.88 & 72.78 & 40.72 & 1.62 & 57.66 & 0.71 & 0.73 \\
\end{tabular}

The diffraction patterns of $\mathrm{Zn}_{1-x} \mathrm{Mn}_{x}$ Te films of various thickness fabricated at $T_{\mathrm{s}}=350{ }^{\circ} \mathrm{C}$ before and after the copper implantation (samples 5-1a - 5-4a) are shown in Fig. 2. The deposited films were characterized by single-phase structures with a stable cubic modification (ZB). As a rule, reflexes from (111), (200), (220), (311), (400), (331), (420), (422) and (511) planes of cubic phases were registered in the diffraction patterns. The peaks (111) had dominating intensities in most cases. This indicated the existence of a growth texture, the axis of which was perpendicular to this plane. This conclusion was confirmed by the calculations, which were performed using the method of the inverse pole figures (Fig. 3a). It can be seen that the maximum value of the pole density is found for the crystallographic planes (111), (222). The texture [111] is traditional for $\mathrm{A}_{2} \mathrm{~B}_{6}$ compounds fabricated using vacuum evaporation [18-20]. Earlier it was found in the $\mathrm{ZnTe}$ films which were fabricated using the same method [16, 17]. Implantation did not change the sample structures. Additional lines of copper were not registered in the diffraction patterns.

We calculated the orientation factor characterizing the film texture perfection for the initial and deposited films after implantation (Table II and Fig. 3b). It was proved that when the substrate temperature increased from $150^{\circ} \mathrm{C}$ to $550^{\circ} \mathrm{C}$, the orientation $f$ factor increased from 0.56 to 2.09. This indicates high quality of the textures of high-temperature deposited films. Implantation of copper into the thin films of solid solution (samples $5-4 a-5-3 a)$ practically did not change the perfection of their textures. At the same time, the texture perfection of thicker films after the implantation increased (samples $5-1 \mathrm{a}-5-2 \mathrm{a})$.

We determined the lattice constant of the solid solution $\mathrm{Zn}_{1-x} \mathrm{Mn}_{x}$ Te in a film state depending on the temperature of material deposition. The experimental values of 


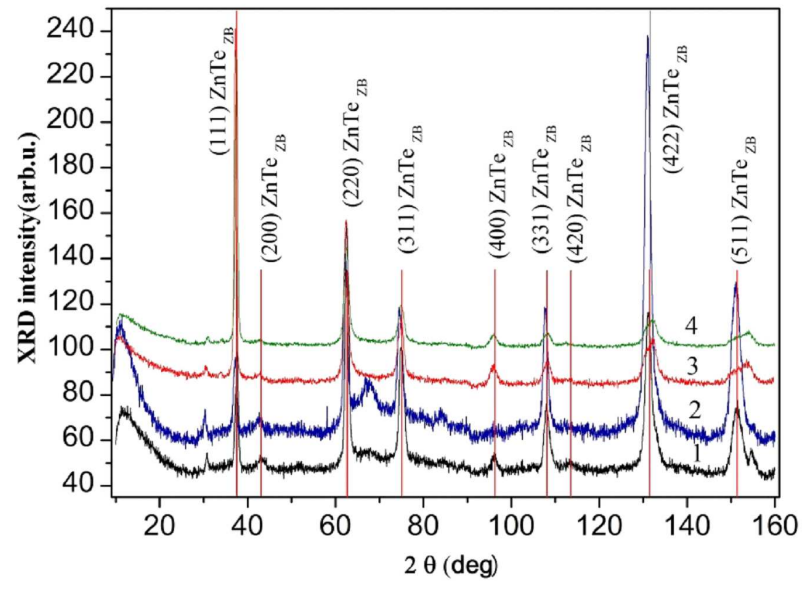

Fig. 2. XRD patterns of the $\mathrm{Zn}_{1-x} \mathrm{Mn}_{x}$ Te films of various thickness before $(1,4)$ and after $(2,3)$ copper implantation.
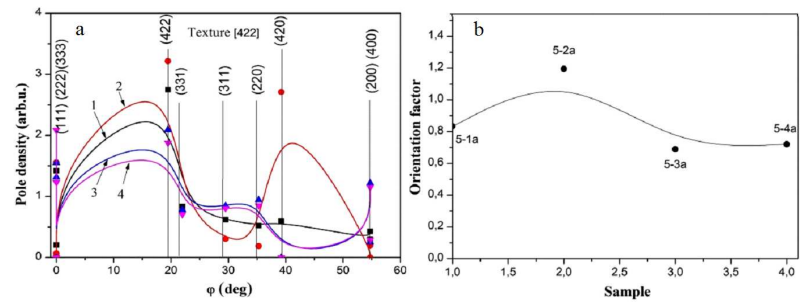

Fig. 3. Pole density $P(h k l)$ of the thin films $\mathrm{Zn}_{1-x} \mathrm{Mn}_{x} \mathrm{Te}$ (a); sample: 5-1a (1), 5-2a (2), 5-3a (3), 5-4a (4), and orientation factor (b).

the material lattice constant $(a=0.60998-0.61043 \mathrm{~nm})$ are lower than those of the ZnTe films fabricated under the same conditions $(a=0.60890-0.61165 \mathrm{~nm})[16,17]$. This is apparently due to the substitution in the lattice of $\mathrm{Zn}$ by $\mathrm{Mn}$ atoms, since the latter have a lower atomic radius $[1,2]$. Some results of $a$ measurements in the $\mathrm{Zn}_{1-x} \mathrm{Mn}_{x}$ Te films before and after $\mathrm{Cu}$ implantation are presented in Table II. It can be seen that the lattice

TABLE II

Lattice constant values of the $\mathrm{Zn}_{1-x} \mathrm{Mn}_{x}$ Te films before and after $\mathrm{Cu}$ implantation.

\begin{tabular}{|c|c|c|c|}
\hline \multirow[b]{2}{*}{ Sample } & \multicolumn{2}{|c|}{$a[\mathrm{~nm}]$} & \multirow[b]{2}{*}{ Note } \\
\hline & $\begin{array}{l}\text { Nelson-Riley } \\
\text { method }\end{array}$ & $\begin{array}{c}\text { Bradley-Jay } \\
\text { method }\end{array}$ & \\
\hline $5-1 a$ & 0.61400 & 0.61154 & $\begin{array}{c}T_{\mathrm{s}}=350^{\circ} \mathrm{C} \\
t=15 \mathrm{~min}\end{array}$ \\
\hline $5-2 a$ & 0.61459 & 0.61322 & $\begin{array}{c}\text { after } \\
\text { implantation }\end{array}$ \\
\hline $5-4 a$ & 0.61192 & 0.60867 & $\begin{aligned} T_{\mathrm{s}} & =350^{\circ} \mathrm{C} \\
t & =5 \mathrm{~min}\end{aligned}$ \\
\hline $5-3 a$ & 0.61288 & 0.60870 & $\begin{array}{c}\text { after } \\
\text { implantation }\end{array}$ \\
\hline
\end{tabular}

constant of the material evidently increased after copper implantation.

\section{Conclusion}

The paper deals with the studies of surface morphology and structural features of the $\mathrm{Zn}_{1-x} \mathrm{Mn}_{x}$ Te films, which were deposited using the CSVS method under various physical and technological deposition regimes. The main points of the conclusion are as following:

1. It was determined that the thin $\mathrm{Zn}_{1-x} \mathrm{Mn}_{x}$ Te films with the thickness of about 2 to $8 \mu \mathrm{m}$ had the grain size $D=0.50$ to $1.12 \mu \mathrm{m}$, which increased with the substrate temperature. The thin films were single-phase with a stable cubic structure. The axial [111] growth of the texture was determined with the help of the inverse pole figure. The orientation factor increased with the substrate temperature.

2. The Mn concentration changed with the growth conditions in the range from 1.61-3.04 at.\%. Scanning of the films surfaces by the proton ( $\mu$-PIXE) revealed the uniform distribution of Mn over their surfaces.

3 . It was found that the experimental values of the lattice constant of $\mathrm{Zn}_{1-x} \mathrm{Mn}_{x}$ Te solid solution $(a=0.60998$ to $0.61043 \mathrm{~nm}$ ) were lower than those of $\mathrm{ZnTe}$ films $(a=0.60980$ to $0.61165 \mathrm{~nm})$ deposited under the same conditions. Copper ion implantation resulted in the increase of the material lattice constant.

4. It was found that the implantation influences on the formation of precipitates in the film composition, texture quantity, and the lattice constant of the film.

\section{References}

[1] J. Kossut, J.A. Gaj, Introduction to the Physics of Diluted Magnetic Semiconductors, Springer Series in Materials Science, Springer, Warsaw 2010.

[2] A. Avdonin, Ph.D. Thesis, Institute of Physics, Polish Academy of Sciences, Warsaw 2010.

[3] S. Kasap, P. Capper, The Springer Handbook of Electronic and Photonic Materials, Springer, Berlin 2007.

[4] L. Feng, D. Mao, J. Tang, R.T. Collins, J.U. Trefny, J. Electron. Mater. 25, 1422 (1996).

[5] W. Wang, G. Xia, J. Zheng, L. Feng, R. Hao, J. Mater. Sci. Mater. Electron. 18, 427 (2007).

[6] D. Stievenard, J.C. Bourgoin, Solid State Phenom. 1-2, 1 (1991).

[7] V.V. Kosyak, A.S. Opanasyuk, P.M. Bukivskij, Yu.P. Gnatenko, J. Cryst. Growth. 312, 1726 (2010).

[8] A.S. Opanasyuk, D.I. Kurbatov, V.V. Kosyak, S.I. Kshniakina, S.N. Danilchenko, Crystall. Rep. 57, 927 (2012).

[9] M.B.H. Breese, D.N. Jamieson, P.J.C. King, Materials Analysis Using a Nuclear Microprobe, Wiley, New York 1996.

[10] V.E. Storizhko, A.G. Ponomarev, V.A. Rebrov, A.I. Chemeris, A.A. Drozdenko, A.B. Dudnik, V.I. Miroshnichenko, N.A. Sayko, P.A. Pavlenko, L.P. Peleshuk, Nucl. Instrum. Methods Phys. Res. 260, 49 (2007). 
[11] Selected powder diffraction data for education and training (Search manual and data cards), International Centre for Diffraction Data, USA 1988.

[12] B.E. Warren, X-ray Diffraction, Dover, New York 1990.

[13] D.K. Bowen, K.B. Tanner, X-ray Metrology in Semiconductor Manufacturing, Taylor \& Francis, Durham 2006.

[14] J.S. Umansky, Y. Skakov, A.N. Ivanov, L.N. Rastorguev, Crystallography, X-ray and Electron Microscopy, Metallurgy, Moscow 1982 (in Russian).

[15] D. Kurbatov, V. Kosyak, M. Kolesnyk, A. Opanasyuk, S. Danilchenko, Integrated Ferroelectr. 103, 32 (2009).

[16] M.M. Kolesnik, D.I. Kurbatov, A.S. Opanasyuk, V.B. Loboda, Semicond. Phys. Quant. Electr. Optoelectron. 12, 35 (2009).
[17] D.I. Kurbatov, V.V. Kosyak, M.M. Kolesnyk, A.S. Opanasyuk, S.N. Danilchenko, Yu.P. Gnatenko, Mater. Chem. Phys. 138, 731 (2013).

[18] C.J. Panchal, A.S. Opanasyuk, V.V. Kosyak, M.S. Desai, I.Yu. Protsenko, J. Nano-Electron. Phys. 3, 274 (2011).

[19] G.I. Rusu, P. Prepeliţă, R.S. Rusu, N. Apetroaie, G. Oniciuc, A. Amariei, J. Optoelectron. Adv. Mater. 8, 922 (2006).

[20] P. Prathap, Y.P.V. Subbaiah, K.T. Ramakrishna, R.W. Miles, Phys. D, Appl. Phys. 40, 5275 (2007). 